\title{
Influence of nutrition and lactation on ovulation and conception in red deer
}

\author{
G.W. ASHER and J.C. POLLARD \\ AgResearch, Invermay Agricultural Centre, Private Bag 50034, Mosgiel, New Zealand \\ geoff.asher@agresearch.co.nz
}

\begin{abstract}
Reproduction incurs a high energetic cost and failure to meet nutritional needs results in reproductive failure. In red deer hinds, the interaction between nutrition, summer lactation and subsequent ovulation/conception is of particular interest for farmed deer production in NZ due to climatic constraints to summer pasture production in many areas. However, few studies have focussed on the potential perturbing effects of poor nutrition on lactational outputs and potential flow-on effects on ovulation/conception. As lacta tion in red deer naturally persists well beyond the autumn mating period, lactational anoestrus (through hormonal feedback mechanisms) is not a normal feature of the species reproduction. However, lactation is of high nutritional cost to the hind and can potentially exert considerable influence on the incidence and timing of conception via changes in hind liveweight, lipid depots and general body condition. Supporting evidence for this hypothesis is derived from studies of wild red deer within habitats marginal to species survival (e.g. Isle of Rhum, Scotland), where climatic variables greatly influence annual reproductive success of hinds. Under such conditions, even the differences in maternal investment (via lactation) required to raise male and female calves have been demonstrated to influence the subsequent success and timing of conceptions. Studies of farmed red deer in Scotland also demonstrated that hinds on different levels of pasture nutrition during lactation exhibited significant differences in conception date, with earlier conceptions favouring hinds on higher levels of nutrition. There is a growing body of evidence from monitoring of farmed red deer in New Zealand that the interaction between lactation and hind body condition score (BCS)/ liveweight influences subsequent conception rate and date. Recent studies on pre-rut versus post-rut calf weaning practices demonstrated effects of lactation on hind BCS and liveweight, calf growth rates and hind conception dates. These studies highlight the need to better understand the "costs" of lactation on reproductive performance, particularly under conditions of nutritional constraints.
\end{abstract}

Keywords: lactation, nutrition, red deer, reproduction

\section{Introduction}

Successful reproduction is crucial to the survival of a species. However, reproduction incurs high energetic costs, especially in placental mammals. Failure to meet the nutritional needs during the reproductive phase of the animals' life cycle invariably leads to ultimate reproductive failure until nutritional deficits are redressed. However, the actual forms of reproductive failure (e.g. anovulation, embryonic wastage, neonatal mortality) vary according to nutritional variables during the various stages of the reproductive process. In this review, we consider the role of nutrition and its interaction with lactation, on seasonal ovulation and conception in farmed red deer and wapiti (Cervus elaphus).

The red deer species is a highly seasonal breeder, with mating occurring in autumn and calving in summer. This strategy ensures optimal chances for neonate survival in highly seasonal temperate regions. The annual reproductive cycle is therefore, aligned with seasonal changes in ambient temperature and feed supply (Lincoln 1985). Even within the most moderate and equable environments, vagaries of climate can cause considerable between-year variation in seasonal feed supply. This leads to considerable variation in reproductive success between years, especially in marginal or harsh environments (e.g. Isle of Rhum; Clutton-Brock et al. 1982). As a generalisation, this variation in success most often reflects annual success in herd conception rate (i.e. proportion of hinds attaining pregnancy), conception date (i.e. within a 2-4 week period over autumn) and neonatal survival (i.e. proportion of calves surviving).

\section{Lactation and ovulation}

In red deer, the interval between parturition/lactogenesis and re-establishment of pregnancy is 130-150 days, whereas lactation can persist for $>300$ days (calves are naturally weaned within the third trimester of the subsequent pregnancy). As mid-lactation normally coincides with conception in adult hinds, lactational anoestrus (through hormonal feedback mechanisms) is clearly not a normal feature of red deer reproduction. However, as lactation is of high nutritional cost to the hind, it can potentially exert considerable influence on the incidence and timing of conception via liveweight, lipid depots and general body condition. As with other mammalian species, we can hypothesise that under conditions of nutritional constraint, excessive energy demands of rearing offspring can ablate or modify the 
timing of ovulation and, consequently conception.

The question posed is ... to what extent have the influences of nutritional constraint over summer, either directly or via interaction with lactation, been demonstrated to influence conception in red deer?

\section{The Isle of Rhum}

The classical studies by Clutton-Brock et al. (1981, 1982) on free-ranging Scottish red deer on the Isle of Rhum, Scotland, have established many of the principles of the influence of nutrition on reproductive success. This population could be regarded as surviving near the limits of their environmental tolerance due to the harsh climatic conditions experienced on the barren island. Detailed life histories over several decades of a significant proportion of the island's hind population have enabled detailed analysis of factors controlling reproductive success.

Clutton-Brock et al. $(1981,1982)$ demonstrated that the ultimate factors affecting reproductive success or failure in red deer hinds are strongly influenced by the quality of the individual's home $r$ ange. A component of this is undoubtedly the effect of nutrition variables on conception rate, foetal survival and neonate survival.

One of the more interesting and telling studies conducted on red deer on Rhum investigated the influence of calf sex on subsequent reproductive performance of their dams (Clutton-Brock et al. 1981). Male calves are born heavier, and suckle longer and more frequently than female calves of the same age. Differences in maternal investment in male and female offspring have associated costs. On Rhum, dams that rear male calves are substantially more likely to fail to produce a calf the following year than those that have reared females; and if they do, they conceive about 11 days later. This indicates strongly the influence of nutrition $\mathrm{x}$ lactation interactions on reproductive performance of red deer.

\section{Historical studies on the relationship between pasture quality, lactational performance and reproductive success}

Early studies on red deer in Scotland demonstrated that lactating hinds on poor quality hill pasture resume oestrus at a later date than non-lactating hinds and frequently fail to ovulate in the year following the birth of a calf (Mitchell et al. 1976; Mitchell \& Lincoln 1973). It has been proposed that this reproductive delay or failure is due to the effect of both lactation and poor planes of nutrition on maternal body condition (Hamilton \& Blaxter 1980; Mitchell et al. 1977). However, Loudon et al. (1983) suggests that the principal influence of low planes of nutrition is to increase the suckling frequency of the calf in response to a decrease in availability of milk. It is this increase in suckling frequency, and perhaps the associated increase in prolactin secretion, which is the major determinant of the reproductive failure, irrespective of maternal body condition.

In support of this hypothesis, Loudon et al. (1983) maintained two groups of red deer hinds on two contrasting levels of pasture nutrition. While liveweights did not vary significantly between the two groups, hinds on the lower plane of nutrition exhibited lower milk yields, higher suckling frequency and increased plasma prolactin concentrations. Furthermore, the low nutrition group was on average 6.2 days later to exhibit oestrus. However, Loudon et al. (1983) did not monitor hind body condition score (as an indicator of body fat reserves), and although average liveweights were not significantly different, hinds on the lower plane of nutrition gained less weight over the lactating period ( 3.8 vs $9.3 \mathrm{~kg}$ ). Therefore, the data are not strong enough to rule out lactational effects on hind body condition as a possible mediator of reproductive delay.

\section{Implications for farming of red deer in New Zealand}

While the jury is still out on direct versus indirect lactational control of reproductive success in red deer, demonstration of carry-over effects of nutrition during lactation on subsequent reproductive performance is unequivocal. There are strong supportive data for such in farmed red deer in New Zealand.

Audigê et al. (1999), using path analysis of multivariate data across 15 red deer farms, concluded that factors associated with high pregnancy rate early (before 1 May) in the mating season included early (late February/early March) weaning of calves (i.e. cessation of lactation before breeding activity) and a body condition score (BCS) of $>2.0$ at mating. The concepts of the influence of BCS on reproductive success has been further expanded by Beatson et al. (2000) and Wilson et al. (2000) using data from various farm monitoring extension projects. They demonstrated that mature hinds with a low BCS $(<2.5)$ were less likely to conceive than hinds of a higher BCS $(>3)$, with the measured difference in conception rates being $10 \%$. Furthermore, hinds in very good condition (BCS of 4-5) generally conceived 5 days earlier than those in poorer condition. Interestingly, Beatson et al. (2000) found little benefit in dynamic increases in BCS between mating and pregnancy scanning, but definite reductions in conception rate with decreases in BCS over the same period. Unfortunately, the data analysed did not include information on changes in BCS occurring before the mating period.

These studies clearly point to an influence of hind 
condition (i.e. fat and muscle reserves) on conception rate and date, but provide little detailed information on the role of lactation, BCS and reproductive performance. However, the early weaning effect on early pregnancy rate (Audigê et al. 1999) hints at an influence of lactation, as it could be argued that early cessation of lactation diverts energy intake by the hind away from calf production and into reinstatement of hind fat and muscle reserves just prior to the rut. This would be seen as a dynamic change in BCS prior to the rut (not measured in these studies).

The impact of early and late weaning practices on hind reproductive performance was studied in more detail by Pollard et al. (2002). Previous studies on the effect of early weaning on conception date of various cervid species have yielded conflicting results, ranging from increased spread in calving dates in pre-rut weaned red deer in Scotland (Blaxter et al. 1988) to no effect of weaning date on the onset of oestrus in fallow deer in Australia (Mulley et al. 1994), to earlier conception dates on Canadian wapiti farms which weaned early compared with those which weaned later (Friedel \& Hudson 1994). It is a general opinion among New Zealand red deer farmers that pre-rut weaning of the calf allows the hind to conceive earlier in the breeding season (Pollard \& Pearse 1998).

Pollard et al. (2002) monitored early-weaned (early March) and late weaned (late May) hind-calf pairs on 10 farms in Otago and Southland over a two-year period. Calves weaned early gained less weight than lateweaned calves. However, mean conception dates were earlier in the early-weaned hinds compared with the lateweaned hinds (by 12 days in Year 1 and 7 days in Year 2). Furthermore, hind BCS in May/June were higher for the early-weaned hinds compared with the late weaned hinds (by 0.5 units in Year 1 and 0.3 units in Year 2). It was concluded that farmers weaning early could expect a positive effect on hind conception date and winter hind BCS, but a negative effect on calf growth rate (Pollard et al. 2002). These data demonstrate a link between lactation and BCS that influences conception date in red deer hinds. Interestingly, the apparent causal relationship was greater in Year 1 than Year 2, probably reflecting the summer drought conditions preceding observations in Year 1. The inference of these observations is that nutritional deficits during lactation will impact negatively on hind BCS and subsequent reproductive performance. It is still conceivable, but far from convincingly demonstrated, that under conditions of severe nutritional constraint, lactation may exert a direct hormonal inhibition of ovulation (seen by Loudon et al. 1983).

Whatever the biological mechanisms, it is clear that lactation can exact a toll on reproductive performance of hinds, and farm management strategies need to include feed planning scenarios for lactating hinds during times of pasture deficit (e.g. summer drought) to ensure optimal subsequent reproductive performance.

\section{REFERENCES}

Audigê, L.J.M.; Wilson, P.R.; Pfiffer, D.U.; Morris, R.S. 1999. Reproductive performance of farmed red deer (Cervus elaphus). New Zealand Journal of Agricultural Research 41(4): 545-553.

Clutton-Brock, T.H.; Albon, S.D.; Guinness, F.E. 1981. Parental investment in male and female offspring in polygynous mammals. Nature 289: 487-489.

Beatson, N.S.; Campbell, A.C.; Judson, H.G.; Wilson, P.R. 2000. Recommendations for improving performance in deer production systems. 1. Improving pregnancy rate and achieving early conception date in breeding hinds. Proceedings of a Deer Course for Veterinarians; Deer Branch New Zealand Veterinary Association, Course No. 17: 917.

Blaxter, K.; Kay, R.N.B.; Sharman, G.A.M.; Cunningham, J.M.M.; Eadie, J.; Hamilton, W.J. 1988. Farming the Red Deer. Rowett Research Institute and the Hill Farming Research Organisation, Department Agriculture and Fisheries, Edinburgh.

Clutton-Brock, T.H.; Guinness, F.E.; Albon, S.D. 1982. Red Deer: Behaviour and Ecology of Two Sexes. Chicago University Press, Chicago 160pp.

Friedel, B.A.; Hudson, R.J. 1994. Productivity of farmed wapiti in Alberta. Canadian Journal of Animals Science 74: 297-303.

Hamilton, W.J.; Blaxter, K.L. 1980. Journal of Agricultural Science 95: 261-273.

Lincoln, G.A. 1985. Seasonal breeding in deer. In: Biology of Deer Production. Eds. Fennessy, P.F.; Drew, K.R. The Royal Society of New Zealand; Bulletin 22: 165-179.

Loudon, A.S.I.; McNeilly, A.S.; Milne, J.A. 1983. Nutrition and lactational control of fertility in red deer. Nature 302: 145-147.

Mitchell, B.; Lincoln, G.A. 1973. Journal of Zoology 171: 141-152.

Mitchell, B.; McCowan, D.; Nicholson, I.A. 1976. Journal of Zoology 180: 107-127.

Mulley, R.C.; English, A.W.; Mylrea, G.E. 1994. Comparative evaluation of pre- and post-rut weaning of fallow deer (Dama dama), to assess fawn growth rate and doe fertility. Proceedings of the Australian Society of Animals Production 20: 297-303.

Pollard, J.C.; Pearse, A.J.T. 1998. Management of red deer at weaning. Proceedings of a Deer Course for Veterinarians; Deer Branch New Zealand Veterinary Association, Course No15: 79-86. 
Pollard, J.C.; Asher, G.W.; Littlejohn, R.P. 2002. Weaning date affects calf growth rates and hind conception dates in farmed red deer (Cervus elaphus). Animal Science 74: 111-116.

Wilson, P.R.; Beatson, N.S.; Campbell, A.C.; Judson,
H.G. 2000. Optimising deer herd conception rate and date: Research and extensions project messages. Proceedings of a Deer Course for Veterinarians; Deer Branch New Zealand Veterinary Association, Course No 17: 37-42. 